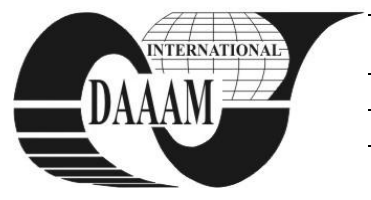

\title{
THE UTILIZATION PROCEDURAL GASEOUS MEDIUM IN MACHINING OF STEEL1.4301 BYTOOLS FROM HSS
}

\author{
BELAN, M[iroslav] \& TARASOVICOVA, A[driana]
}

\begin{abstract}
Machining austenitic chrome-nickel steel is technologically difficult and complex process. Physical, mechanical and chemical properties of this material require appropriate choice of cutting parameters with respect to the limit stability of the cutting process, the choice of suitable cutting tools and cutting environment. There was executed partial experiment under the research in area of the machining by cutting materials made of HSS and HSS-PM, where steel 1.4301 was machined by uncoated tools from HSS. As the process medium was used ozone in this case. Despite the anticorrosion and antioxidant properties of steel 1.4301 was applied just ozone, because our goal was to use lubricating and adsorption properties of ozone on uncoated tool and thereby reduce the coefficient of friction.
\end{abstract}

Keywords: machining, HSS steel, ozone, stainless steel

\section{INTRODUCTION}

The problem with machining of austenitic chrome-nickel steel is that this material strain hardening and it has low thermal conductivity. This steel is prone to sticking to the tool, which can cause breakage of the tool and the loss of his cutting ability. Effect of hardening can be so intensive, that on machined surface can be created areas with the extremely high hardness, 400 to $500 \mathrm{HB}$ with a thickness of $0.1 \mathrm{~mm}$. This is very important in the choice of cutting tool geometry, while a negative rake angle and cutting tool wear magnify hardened layer. Positive rake angle and a sharp cutting edge tool operating on the contrary. As for cutting conditions it is appropriate to choose the depth of cut and feed so that tool got behind hardened layer in machining, respectively, to avoid high strain rate material. The reason for the cold-hardening is one of the transformations of hypothermic austenite, namely the transformation of austenite to martensite at high strain rate. Low thermal conductivity is another issue that affects the choice of cutting tool material. Heat from the primary and secondary plastic deformation is not preferably vented chips and also heat transfer from the zone of cutting back the material is limited. The reason is the high content of chromium as alloying elements, which reduces the thermal and electrical conductivity. In the cutting zone remains greater amount of heat that adversely affects tool life. (Bach, 2009 ), (Humár, 2008), (Kudela,1997), (Misik, et. al. 1998), (Monika et. al, 2011), $(* * *, 2011)$

\section{RESEARCH IN MACHINING OF STAINLESS STEELS}

This partial experiment was carried out on the based combinations the knowledge gained from research in the area called green machining and low speed cutting (milling). When cutting environment was selected attention was focused to greening process medium, its lubricating effects, as well as its ability to better penetrate the locality cut. For low speed cutting there were applied cutting conditions where lower the strain rates were certain and cutting power $(\mathrm{Q})$ by the formula was maintained:

$$
Q=a_{p} \times a_{e} \times v_{f} \times 10^{-3}\left(\mathrm{~cm}^{3} / \mathrm{min} .\right)
$$

- $a_{\mathrm{p}}$ - axial depth of cut

- $\mathrm{a}_{\mathrm{e}}$ - radial depth of cut

- $\mathrm{v}_{\mathrm{f}}$ - feed rate $[1,8,11]$

The most commonly utilized cutting materials for machining corrosion - resistant steel is sintered carbide. Sintered carbides are used mostly for finishing operations at higher cutting speeds, what is limiting factor in machining of corrosion-resistant steel because of the low thermal conductivity of workpiece. As the cutting material was chosen high speed steel. The cutting material is primarily used in machining at lower cutting speeds and everywhere where cutting forces are changing the amplitude and frequency. Tools made of HSS (High Speed Steels) and HSS-PM (prepared via Powder Metallurgy) are characterized by high toughness and sufficient hardness at temperatures cutting up to $500^{\circ} \mathrm{C}$. Cutting (milling) tools were made of HSS-Co. Uncoated tools from HSS are recommended by HSS Smart Guide Milling that they are capable to machine effectively of austenitic corrosionresistant steel speeds from 10 to $15 \mathrm{~m} / \mathrm{min}$.. One of the advantages of these tools, compared to sintered carbides is also the possibility of coat removal, grinding and re-coating after wear (Lukovics, et. al. 2008),(Miškovičová, et. al. 1997), (Miškovičová, et. al. 1998) .(***,2011).

\subsection{Cutting environment}

As the process medium was used ionized air (ozone), highly reactive ecological process medium. It is characterized by strong oxidizing effects, good penetration into the cutting zone and a relatively high thermal conductivity. Since the workpiece has been chrome-nickel austenitic steels with high chromium content (17 to $19.5 \%$ ) and nickel (8 to 10.5\%) it was not possible to make full use of lubricating and wetting properties of ozone applied. It is the chemical composition of steel not only prevents corrosion formation but also the oxidation process. Based on theoretical knowledge was predicted adsorption of ozone on tools because there were used cutters HSS-Co which were not coated by method PVD and cutters contained only approximately a quarter of chromium content of machined austenitic steel. Just PVD coating method provides resistance to oxidation tools. Creating a thin lubricating layer would reduce the friction coefficient at the point of cutting., (Humár, 2008), (Matija, 2009), (Vasilko, 2007), (***, 2011)

\subsection{Parameters of machining and of the tools}

Tests were carried out simultaneous milling face - peripheral cutters for these cutting conditions on Tab.1. Length milling surface was in each case $100 \mathrm{~mm}$. Were used uncoated face peripheral cutters HSS-Co with the parameters: diameter 16 
$\mathrm{mm}, 4$ teeth, regular pitch of teeth, one tooth cutter through the middle, radialk rake angle $\gamma=12^{\circ}$.

\section{RESULTS AND CONCLUSIONS}

The values of roughness profile $\mathrm{Rz}$ shown in Fig. 1 were measured device Mitutoyo SJ-400. Tool wear was checked after each crossing tool. There was used measuring magnifying glass Mitutoyo. There were checked face and back tool surfaces.

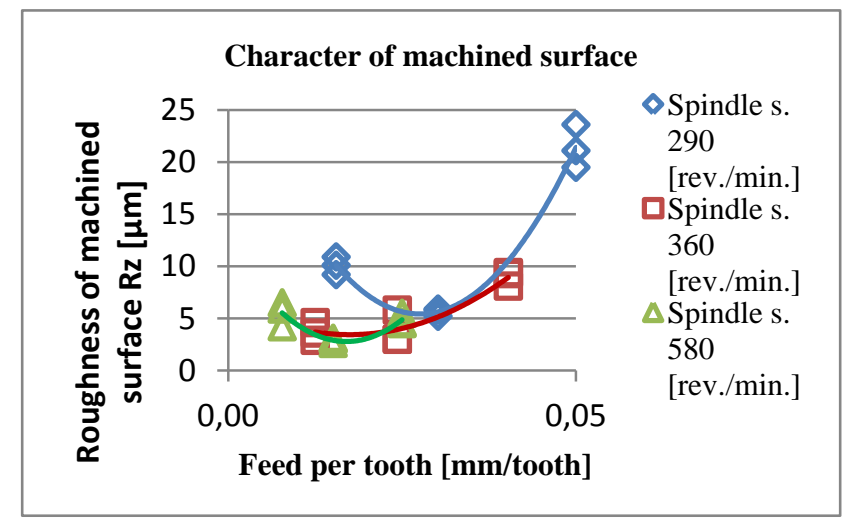

Fig. 1 Measured values of Rz

\begin{tabular}{|c|c|c|c|}
\hline $\begin{array}{c}\text { Revolutions } \\
\text { or } \\
\text { cutting speed } \\
\text { (rev.) or } \\
\left(\mathrm{m}^{\left.* \mathrm{~min}^{-1}\right)}\right.\end{array}$ & $\begin{array}{c}\text { feed per } \\
\text { tooth } \\
\mathrm{f}_{\mathrm{t}} \text { [mm/tooth] }\end{array}$ & $\begin{array}{c}\text { radial depth } \\
\text { of cut } \\
\mathrm{a}_{\mathrm{e}}[\mathrm{mm}]\end{array}$ & $\begin{array}{c}\text { axial } \\
\text { depth } \\
\text { of cut } \\
\mathrm{a}_{\mathrm{p}} \text { [mm] }\end{array}$ \\
\hline $290 / 14.6$ & 0.0155 & 8 & 2 \\
\hline $290 / 14.6$ & 0.03 & 8 & 2 \\
\hline $290 / 14.6$ & 0.05 & 8 & 2 \\
\hline $360 / 18$ & 0.0125 & 8 & 2 \\
\hline $360 / 18$ & 0.024 & 8 & 2 \\
\hline $360 / 18$ & 0.04 & 8 & 2 \\
\hline $580 / 29$ & 0.0078 & 8 & 2 \\
\hline $580 / 29$ & 0.015 & 8 & 2 \\
\hline $580 / 29$ & 0.025 & 8 & 2 \\
\hline
\end{tabular}

Tab. 1 Cutting parameters

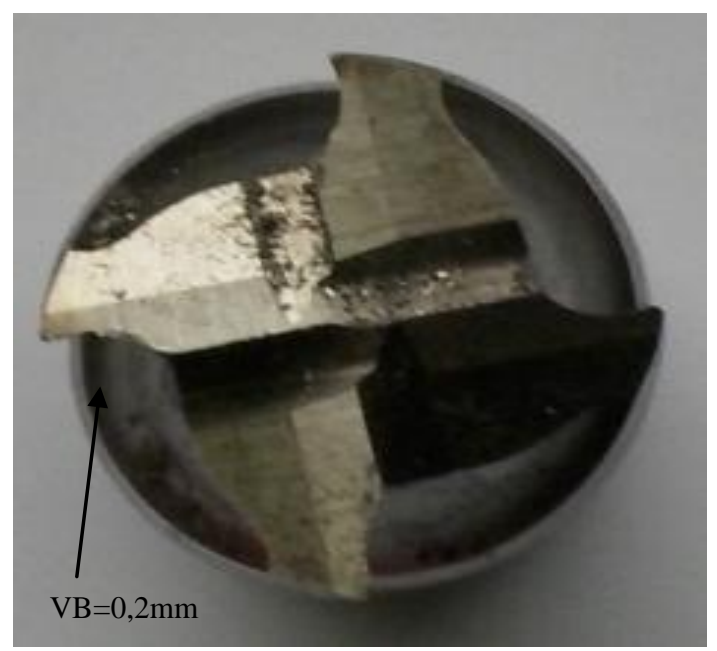

Fig. 2 Cutter wear on the back surface

The best values of roughness, characterized by height of roughness profile from ten points of $\mathrm{Rz}$, were achieved at spindle speeds $580 \mathrm{rev} / \mathrm{min}$. and feed per tooth $0,015 \mathrm{~mm}$, it was concretely $2,9 \mu \mathrm{m}$. Similar values were achieved also at revolutions of $360 \mathrm{rev} / \mathrm{min}$. and feeds per tooth 0,0125 and $0,0243 \mathrm{~mm}$, it was 3,7 and $3,9 \mu \mathrm{m}$. The cooling effect of process medium and its ability to penetrate into the cutting area was sufficient. By adjusting the diameter of the outlet nozzle could be cooling effect additionally increased. Lower cutting speeds compared to cutting speeds applied in machining sintered carbides ensure that there is no hardening thin layer of workpiece before the cutting tool, or workpiece is not exposed to high strain rate. In carrying out further experiments it is possible to take advantage of tools from HSS to machine with high axial depth of cut. Increasing the axial depth of cut would reduce the burden of ensuring the secondary blade unit of its length and also by increased cutting power. To increase the durability of cutting tools could be used for flow cooled air to $5^{\circ} \mathrm{C}$ and more minus ${ }^{\circ} \mathrm{C}$. On the test tools were also observed on the back surface wear VB as well as other forms of wear. The maximum wear value $\mathrm{VB}$, which was measured on the back surface of cutting tools after time 20 minutes was $0,2 \mathrm{~mm}$. In the case of one tool was observed brittle fracture, where was the destruction of three teeth and thus the loss of the cutting tool capabilities. Realized experiments showed that the examination of cutting materials for the application areas is justified, not only in terms of technology, but also in economic terms.

\section{REFERENCES}

Bach, P. (2009). HSS-PM tools for powerful and economical machining of titanium alloys (in Czech language), Available from: http://www.infocube.cz/images/machiningtooling/clanky/CVUT_HSS\%20nastroje $\% 20 \mathrm{z} \% 20 \mathrm{PM} \% 20 \mathrm{o}$ celi\%20pro\%20vykonne\%20a\%20ekonomicke\%20frezova ni\%20titanovych\%20slitin_50.pdf

Humár, A. (2008). Materials for cutting tools (in Czech language), MM publishing s.r.o, ISBN 978-80-254-2250-2, Prague

Kudela, M.(translator) (1997). Sandvik- Guide for machining (in Czech language), Scientia, s.r.o, ISBN 91-97 22 99-4-6, Prague

Lukovics, I.; Bílek, O. (2008). High Speed Grinding Process, Manufacturing Technology, 8/ 2008, 12-18. ISSN 12132489.

Matija, R.; Mišík, L.; Hloch, S. (2009). Use of process media (in Slovak language), Strojárstvo/Strojárenství (Engineering), 2/2009, 2-3. ISSN 1335- 2938

Misik, L.; Hloch S.; Vagaska A.; et al. (2008) Side Milling Factors Analysis Affecting The Surface Irregularities Of High-Grade Steel E295, Tehnicki Vjesnik-Technical Gazette, Volume: 15, Issue: 2 Pages: 19-23, ISSN 13303651

Miškovičová, M.; Fáberová, M.; Monka, P. et al. (1998) New tool steels produced from powders, Acta Metalurgica Slovaca, No. 4. , ISSN 1338-1156, p. 276-281

Miškovičová, M; Fáberová, M.; Monka et al. (1997): New High Alloyed steels Prepared Via Powder Metallurgy, Proceedings of the 5th European Conference on Advanced Materials and Processes and Applications, L.A.J.L. Sarton and H.B. Zeedjik, Eds., Maastricht, Neederland

Monka P., Monková K. (2011) Selected dynamic factors influence on cutting material, Proceedings of Conference „New Technologies In Manufacturing“, Brno, ISBN 97880-214-4267-2

Vasilko, K. (2007). Analitical Theory of Chip Machining (in Slovak Language), Fakulta výrobných technológií TU v Košiciach, so sídlom v Prešove,ISBN: 978-80-8073-759-7, Prešov

*** (2011) HSS Smart Guide 01 Introduction,

Available from: http://www.hssforum.com/SmartGuideEN.htm *** (2011) Inox spol. s r.o., Properties of stainless steels (in Slovak language), Available from: http://www.inoxspol.cz/nerezova-ocel-14301.html

*** (2011) Milling tools (in Slovak Language), Available from::http://www.zps-fn.cz/ 